\title{
CORRIGENDUM
}

\section{Spot urine-guided salt reduction is effective in Japanese cardiology outpatients}

\author{
Shinichi Hirota, Tsuneaki Sadanaga, Hideo Mitamura and Keiichi Fukuda
}

Hypertension Research (2012) 35, 1120; doi:10.1038/hr.2012.118

Correction to: Hypertension Research (2012) 35, 1069-1071; doi:10.1038/hr.2012.98; published online 5 July 2012

The authors of the above paper noticed an error in the publication of this article. In the 'Methods' section, the equation used to estimate daily salt excretion should have read:

Estimated 24-h urinary salt excretion (g per day $)=1.285 \times\left(\mathrm{Na}\left(\mathrm{mEql}^{-1}\right) /\right.$ $\mathrm{Cr}\left(\mathrm{mgl}^{-1}\right)$ in spot urine $\times$ expected $24-\mathrm{h} \mathrm{Cr}$ excretion $)^{0.392}$, where expected 24-h Cr excretion $(\mathrm{mg}$ per day) $=-2.04 \times$ age (year old) $+14.89 \times$ weight $(\mathrm{kg})+16.14 \times$ height $(\mathrm{cm})-2244.45$.

Article with correct equation now appears in this issue. The online html and pdf versions have also been rectified. 